Supporting Information

\title{
Structural Control of Boronic Acid Ligands Enhances Intratumoral Targeting of Sialic Acid to Eradicate Cancer Stem-Like Cells
}

Thahomina Khan ${ }^{1}$, Kazunori Igarashi ${ }^{1,2}$, Ami Tanabe $^{1}$, Taiki Miyazawa ${ }^{3}$, Shigeto Fukushima6, Yutaka Miura5 ${ }^{5}$, Yu Matsumoto², Tatsuya Yamasoba ${ }^{2}$, Akira Matsumoto ${ }^{3,4}$, Horacio Cabral $^{1 *}$ and Kazunori Kataoka $^{6,7^{*}}$

${ }^{1}$ Department of Bioengineering, School of Engineering, The University of Tokyo, 7-31 Hongo, Bunkyo-ku, Tokyo 113-8656, Japan.

${ }^{2}$ Department of Otorhinolaryngology Head and neck Surgery, Graduate school of Medicine, The University of Tokyo, 7-3-1 Hongo, Bunkyo-ku, Tokyo 113-8655, Japan.

3/nstitute of Biomaterials and Bioengineering, Tokyo Medical and Dental University, 2-3-10 Kanda-Surugadai, Chiyoda-ku, Tokyo 101-0062, Japan.

${ }^{4}$ Kanagawa Institute of Industrial Science and Technology, Kawasaki 213-0012, Japan

${ }^{5}$ Laboratory for Chemistry and Life science, Institute of Innovative Research, Tokyo Institute of Technology, 4259 Nagatsuta, Midori-ku, Yokohama 226-8503, Japan. ${ }^{6}$ Innovation Center of NanoMedicine (iCONM), Kawasaki Institute of Industrial Promotion, 3-25-14 Tonomachi, Kawasaki-ku, Kawasaki 210-0821, Japan 7Institute for Future Initiatives, The University of Tokyo,7-3-1 Hongo, Bunkyo-ku, Tokyo 113-0033, Japan.

${ }^{*}$ Corresponding author

Prof. Kazunori Kataoka kataoka@ifi.u-tokyo.ac.jp

Prof. Horacio Cabral horacio@bmw.t.u-tokyo.ac.jp 


\subsection{Materials}

a-Methoxy-w-aminopropyl-poly(ethylene glycol) (MeO-PEG-NH 10,000) and $\alpha$-Acetal- $\omega$-aminopropyl-poly(ethylene glycol) (acetal-PEG-NH 12,000 and 5,500) were purchased from NOF Co., Inc. (Tokyo, Japan). $\gamma$ - Benzyl-Lglutamate N-carboxyanhydride (BLG-NCA) was purchased from Chuo Kaseihin Co., Inc. (Tokyo, Japan). Amine-PEG ${ }_{2 k}-\mathrm{DBCO}$ was purchased from Nanocs (New York, USA). Acetic anhydride (>97\%), sodium hydroxide (96\%), 4-(4,6-dimethoxy-1,3,5triazin-2-yl)-4-methylmorpholinium chloride n-hydrate (DMT-MM), N,Ndimethylformamide (DMF), triethylamine (TEA, >99\%), dimethyl sulfoxide (DMSO) (>99\%) and 3-aminophenylboronic acid (PBA) were obtained from Wako Pure Chemical Co., Inc. (Osaka, Japan). Silver nitrate (AgNO3, 99.999\%) was purchased from Aldrich Chemical Co., (Milwaukee, WI). Sodium cyanoborohydride $\left(\mathrm{NaBH}_{3} \mathrm{CN}\right)$ was purchased from Tokyo Chemical Industry Co., Inc. (Tokyo, Japan). Alexa Fluor 555 succinimidyl ester, Alexa Fluor 647 succinimidyl ester and LysoTracker Green DND-26 were purchased from Life Technologies Corporation (Tokyo, Japan). 5Boronopicolinic acid (5-BPA) was obtained from Santa Cruz Biotechnology, Inc. (Texas, United States). Sialic Acid (NANA) Assay Kit was purchased from Abcam (Cambridge, United Kingdom). Neuraminidase (Sialidase) from Clostridium perfringens were purchased from Roche Diagnostics $\mathrm{GmbH}$. (Mannheim, Germany). Dichloro (1,2-diaminocyclohexane) platinum ( II ) (DACHPtCl2), Alizarin red S (ARS) and dulbecco's modified eagle's medium (DMEM) was obtained from Sigma-Aldrich Co. (ST. Louis, U.S.A). Fetal bovine serum (FBS) was purchased from Dainippon Sumitomo Pharma Co., Ltd. (Osaka, Japan). Phosphate-buffered saline (PBS) and oxaliplatin was purchased from Wako Pure Chemical Industries Ltd. (Osaka, Japan). Cell Counting Kit-8 was purchased from Dojindo Laboratories (Kumamoto, Japan). Isoflurane was purchased from Pfizer Inc. (New York, USA). Matrigel Matrix was purchased from CORNING (New York, USA). Head and neck cancer with normal tissue array (HN483a) was purchased from Biomax (Derwood, USA). Blocking One solution was purchased from Nacalai Tesque,Inc (Kyoto, Japan). Alexa Fluor 488 goat anti-mouse lgG $(H+L)$, Alexa Fluor 594 donkey anti-rat lgG $(H+L)$, Alexa Fluor 488 conjugated lectin HPA From Helix pomatia (edible snail) was purchased from ThermoFisher Scientific (Massachusetts, USA). Alexa Fluor 488- and Alexa Fluor 647conjugated Wheat Germ Agglutinin was purchased from Life Technologies (California, 
USA). CD44v9 antibody (anti-human, rat; clone number: RV3) was purchased from CosmoBio (Tokyo, Japan). Involucrin antibody (anti-human, mouse monoclonal; clone number: SY5) was purchased from Abcam (Cambridge, United Kingdom).

\subsection{Cell line}

Human oral carcinoma (HSC2) cells were purchased from Cell Bank, Riken BioResource Center (Tsukuba, Japan). HSC2 cells were maintained in Dulbecco's modified Eagles medium (DMEM) containing 10\% of fetal bovince serum (FBS) and $1 \%$ of penicillin and streptomycin in a humidified atmosphere containing $5 \% \mathrm{CO}_{2}$ at $37^{\circ} \mathrm{C}$. BALB/c mice nu/nu (female; age 6 weeks;) were purchased from Charles River Japan (Kanagawa, Japan). All experiments were performed in accordance with the Guidelines for the Care and Use of Laboratory Animals as stated by the University of Tokyo.

\subsection{Synthesis of polymers}

a-Azide- $\omega$-aminopropyl-poly(ethylene glycol) (azide-PEG-NH synthesized following previously reported method ${ }^{1}$. Methoxy-poly(ethylene glycol)- $b$ poly $\left(\gamma\right.$-benzyl-L-glutamate) (MeO-PEG ${ }_{12 \mathrm{~K}}-b$-PBLG) (molecular weight of PEG $\left(\mathrm{M}_{\mathrm{n}, \mathrm{PEG}}\right)$ $=12,000$, degree of polymerization of PBLG $\left.\left(\mathrm{DP}_{\mathrm{PBLG}}\right)=40\right)$, acetal-poly (ethylene glycol)-b-poly( $\gamma$-benzyl-L-glutamate) (acetal-PEG ${ }_{12 \mathrm{~K}}-b-\mathrm{PBLG}$ ) (molecular weight of PEG $\left(M_{n, P E G}\right)=12,000$, degree of polymerization of PBLG $\left.\left(D_{P B L G}\right)=40\right)$ and azidepoly(ethylene glycol)-b-poly( $\gamma$-benzyl-L-glutamate) (azide-PEG ${ }_{11 K}-b$-PBLG) (molecular weight of PEG $\left(\mathrm{M}_{\mathrm{n}, \mathrm{PEG}}\right)=11,000$, degree of polymerization of PBLG $\left.\left(D_{\mathrm{PBLG}}\right)=40\right)$ were synthesized through previously reported method ${ }^{1,2}$. The molecular weight distribution of both $\mathrm{MeO}-\mathrm{PEG}_{12 \mathrm{~K}}-b-\mathrm{PBLG}$ and acetal-PEG ${ }_{12 \mathrm{~K}}-b$ PBLG was 1.03 , and that of azide-PEG ${ }_{11 \mathrm{~K}}-b-\mathrm{PBLG}$ was 1.02 , measured by gel permeation chromatography (GPC, column: TSK-gel G3000 $0_{H R}$, G4000 $_{H H R}$ ) (Tosoh Co., Inc., Yamaguchi, Japan); eluent: DMF having $10 \mathrm{mM} \mathrm{LiCl}$; flow rate $0.8 \mathrm{ml} / \mathrm{min}$; detector: RI (refractive index); temperature: $25^{\circ} \mathrm{C}$ (Supplementary Figure S1B, D and F). DP $P_{P B L G}$ of MeO-PEG $12 \mathrm{~K}-b-P B L G$, acetal-PEG ${ }_{12 K}-b-P B L G$ and azide-PEG ${ }_{11 K}-$ $b$-PBLG were calculated by comparing the proton units of ethylene units of PEG ($\left.\mathrm{OCH}_{2} \mathrm{CH}_{2}: \delta=3.7 \mathrm{ppm}\right)$ with the phenyl groups of PBLG $\left(-\mathrm{C}_{6} \mathrm{H}_{5-:}: \delta=7 \mathrm{ppm}\right)$ by ${ }^{1} \mathrm{H}-$ NMR spectroscopy (JEOL ECS-400; JEOL Inc., Tokyo, Japan); solvent: DMSO-d ${ }_{6}$, 
temperature: $80^{\circ} \mathrm{C}$ (Supplementary Figure S1A, C and E). Methoxy-poly(ethylene glycol)-b-poly(L-glutamic acid) (MeO-PEG ${ }_{12 K}-b$-PLGA) and acetal-poly(ethylene glycol)-b-poly(L-glutamic acid) (acetal-PEG ${ }_{12 K}-b$-PLGA) were obtained by deprotecting MeO-PEG $12 K-b-P B L G$ and acetal-PEG ${ }_{12 K}-b-P B L G$ in $0.5 \mathrm{~N} \mathrm{NaOH}$ at room temperature overnight. Deprotection of the benzyl ester group was confirmed by ${ }^{1} \mathrm{H}-\mathrm{NMR}$ (solvent: $\mathrm{D}_{2} \mathrm{O}$; temperature: $25^{\circ} \mathrm{C}$ ).
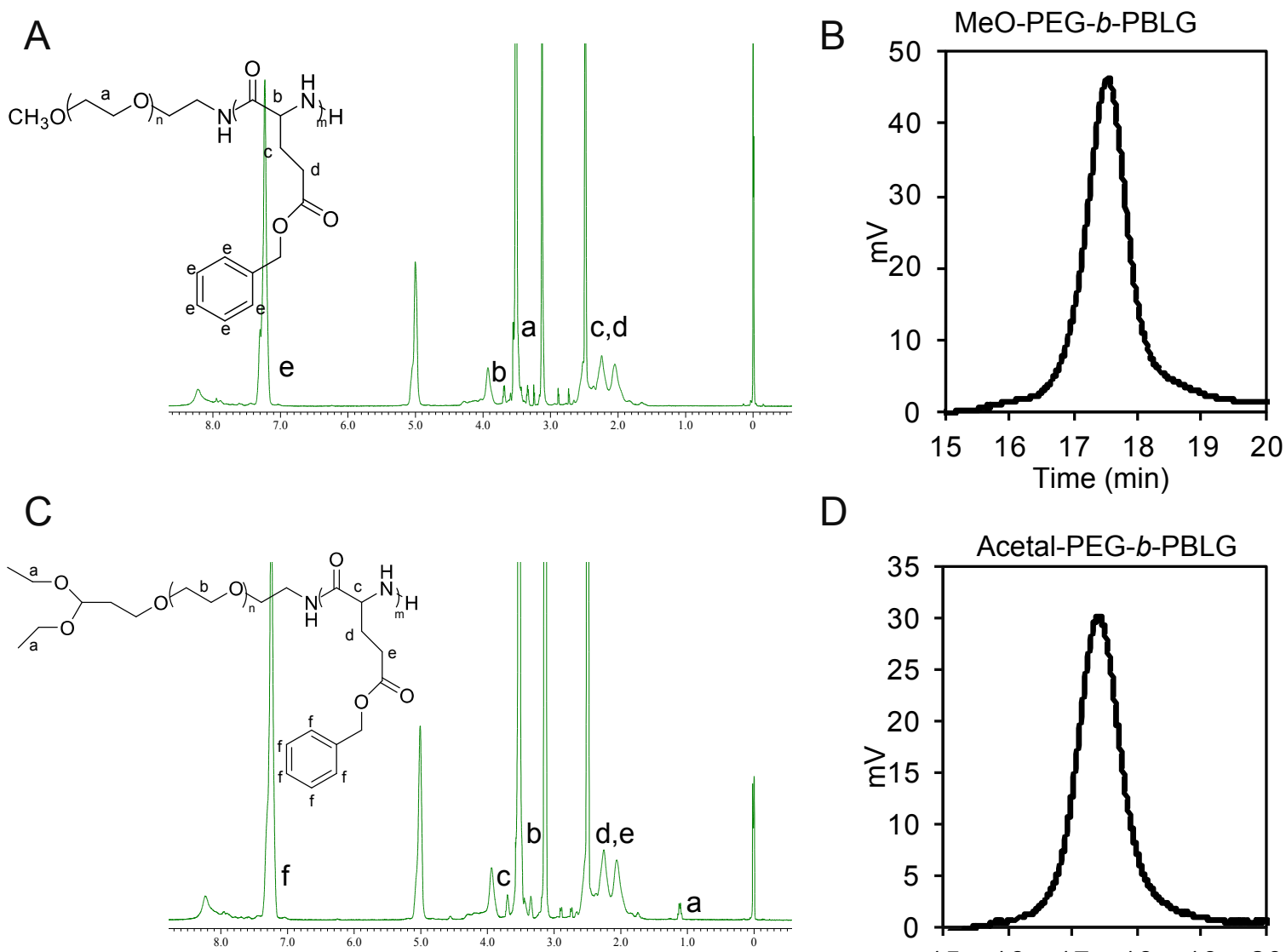

D

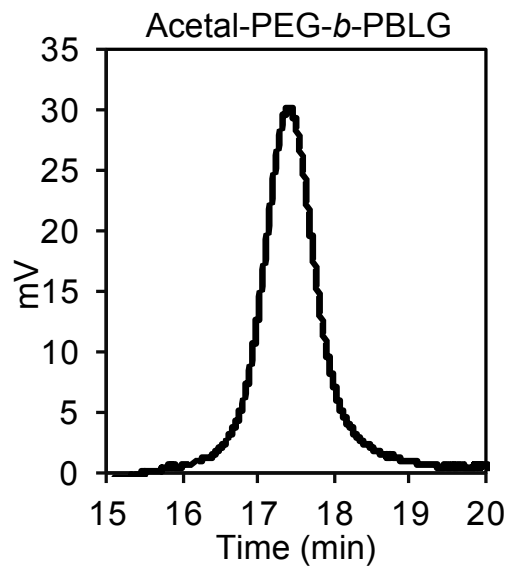

$$
\text { E }
$$

$$
\mathrm{F}
$$

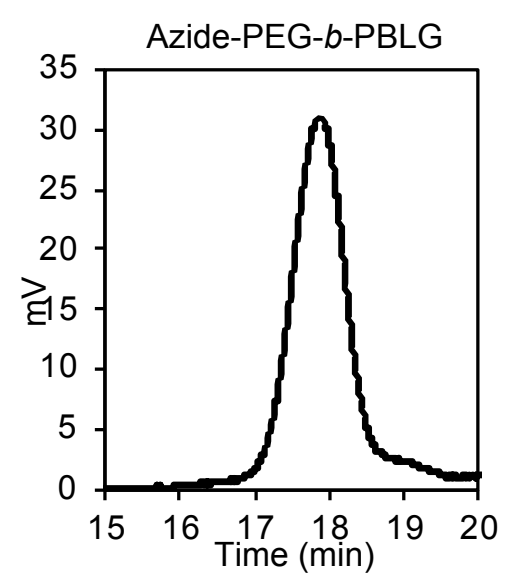

Supplementary Figure S1. ${ }^{1} \mathrm{H}-\mathrm{NMR}$ Spectra and GPC chromatograms of A, B: MeO$\mathrm{PEG}_{12 \mathrm{~K}}-b-\mathrm{PBLG} \mathbf{C}, \mathbf{D}$; Acetal-PEG ${ }_{12 \mathrm{~K}}-b-\mathrm{PBLG}$ and E, F: Azide-PEG ${ }_{11 \mathrm{~K}}-b-\mathrm{PBLG} .{ }^{1} \mathrm{H}-$ 
NMR measurements were done in DMSO- $d_{6}$, at $80^{\circ} \mathrm{C}$. GPC was done in DMF containing $10 \mathrm{mM} \mathrm{LiCl}$ at $0.8 \mathrm{ml} / \mathrm{min}$ (detector: refractive index).

1.4 Conjugation of 5-BPA to block copolymers

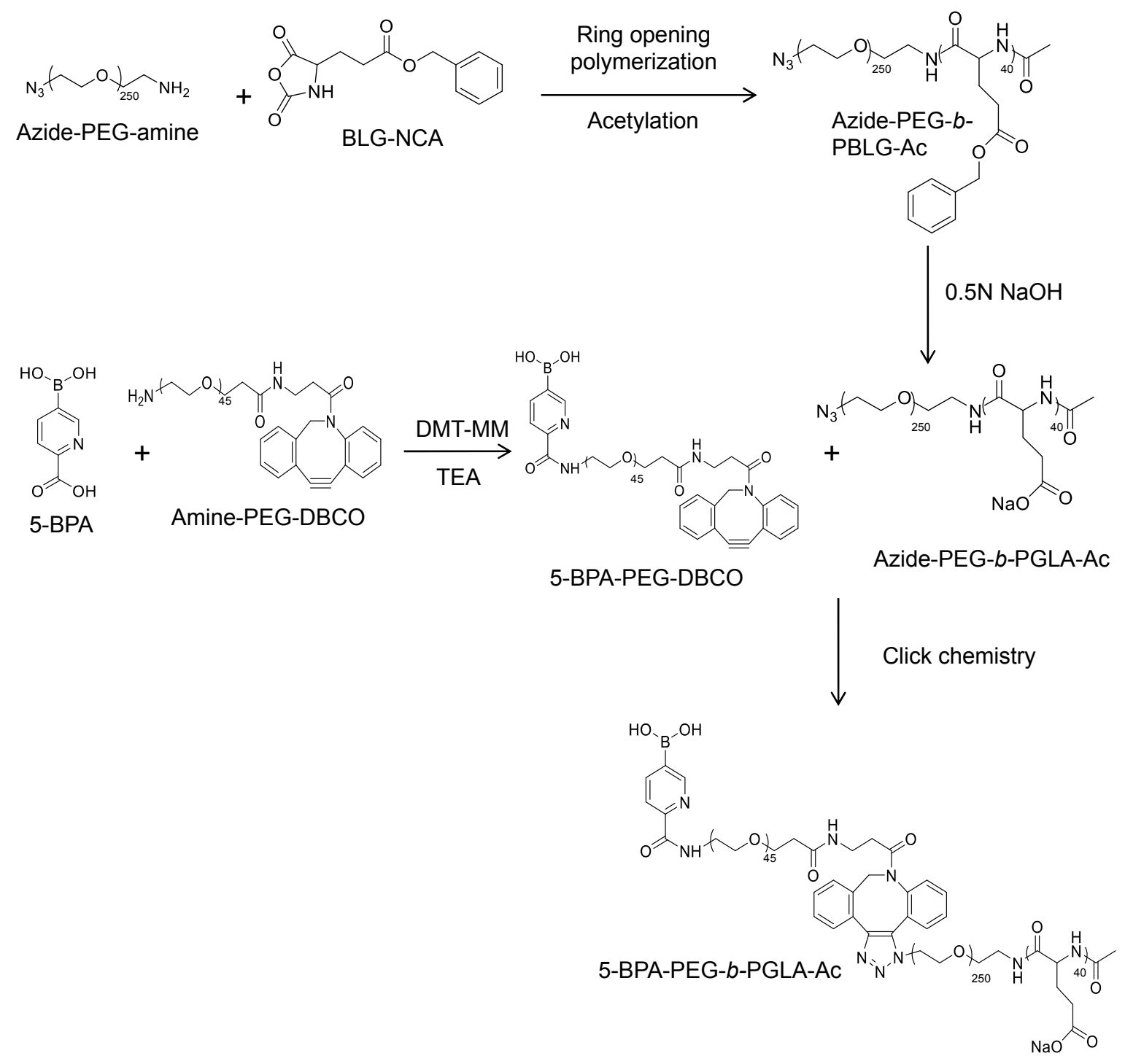

Supplementary Figure S2. Synthesis scheme of $5-B P A-P E G_{2 K+11 K}-b-P L G A-A c$ block copolymer.

$\omega$-amino group of azide-PEG ${ }_{11 \mathrm{~K}}-b$-PBLG was capped by acetylation reaction to obtain azide-PEG ${ }_{11 \mathrm{~K}}-b$-PBLG-Ac. Azide-PEG ${ }_{11 \mathrm{~K}}-b-\mathrm{PBLG}-\mathrm{Ac}$ was stirred in $0.5 \mathrm{~N} \mathrm{NaOH}$ overnight to remove the benzyl ester group. Azide-PEG ${ }_{11 \mathrm{~K}}-b$-poly(L-glutamic acid)-Ac (azide-PEG ${ }_{11 \mathrm{~K}}-b-\mathrm{PLGA}-\mathrm{Ac}$ ) was obtained after purification and freeze drying. 10 fold molar excess of 5-BPA was activated using DMT-MM in DMSO and added to a reaction mixture of 5 fold molar excess of amine-PEG ${ }_{2 K}-D B C O$ with TEA. This reaction mixture was kept stirring for overnight and added to azide-PEG ${ }_{11 \mathrm{~K}}-b$-PLGA- 
Ac. The mixture was further stirred for $24 \mathrm{~h}$ and then incubated at $-20^{\circ} \mathrm{C}$. After $24 \mathrm{~h}$ of incubation reaction mixture was defrosted and purified by dialysis first against DMSO

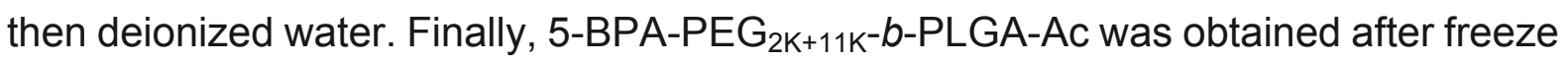
drying (Supplementary Figure S2). Conjugation of 5-BPA was confirmed by ${ }^{1} \mathrm{H}-\mathrm{NMR}$ through presence of protons from pyridine ring ( $\delta=7.9 \mathrm{ppm}, 8.2 \mathrm{ppm}, 8.8 \mathrm{ppm}$ ) of 5BPA (Solvent: $\mathrm{D}_{2} \mathrm{O}$; Temperature: $25^{\circ} \mathrm{C}$ ) (Supplementary Figure S3).

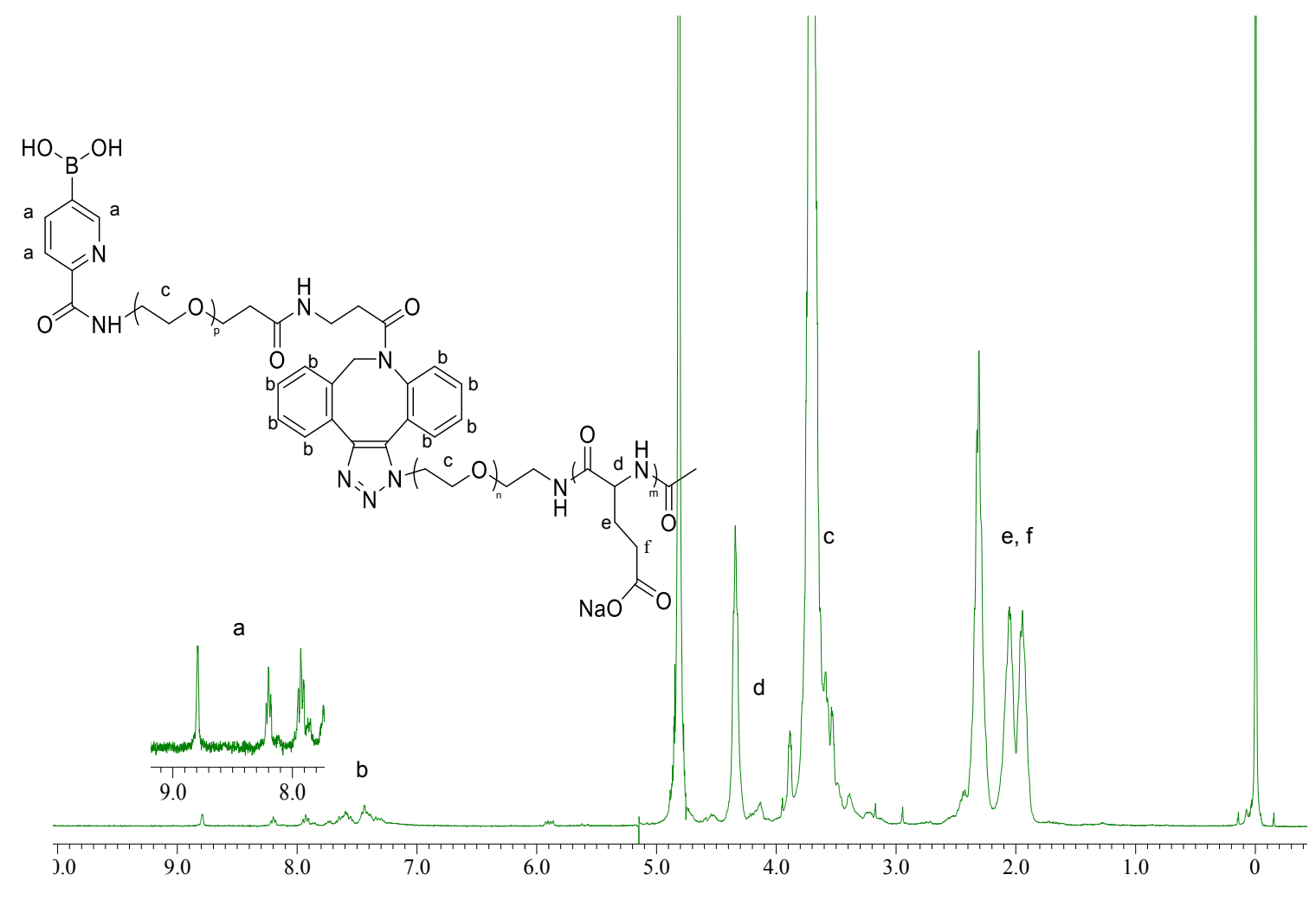

Supplementary Figure S3. ${ }^{1} \mathrm{H}-\mathrm{NMR}$ Spectra of $5-B P A-P E G_{2 K+11 K}-b-P L G A-A c$ block copolymer. ${ }^{1} \mathrm{H}-\mathrm{NMR}$ measurement was done in $\mathrm{D}_{2} \mathrm{O}$ at $25^{\circ} \mathrm{C}$.

\subsection{Conjugation of PBA to block copolymers}

The conjugation of PBA to acetal-PEG ${ }_{12 K}-b-P L G A$ was done by following a previous strategy with minor modification ${ }^{2}$. First, the acetal group of acetal-PEG ${ }_{12 K}-b-P L G A$ was deprotected and converted to aldehyde using $0.1 \mathrm{M} \mathrm{HCl}$ having 10 fold molar excess of PBA. The solution was then stirred for $2 \mathrm{~h}$ and neutralized to $\mathrm{pH} 7.0$ using $0.1 \mathrm{M}$ $\mathrm{NaOH}$. After neutralization, reaction mixture was stirred for $1 \mathrm{~h}$. The aldehyde group reacts with the amine of PBA present in the solution which formed Schiff base. The formed Schiff base was converted to secondary amine by adding 10 fold molar excess of $\mathrm{NaBH}_{3} \mathrm{CN}$ and this mixture was further stirred for 3 days. The obtained polymer was 
purified using deionized water and lyophilized. The PBA conjugation was confirmed by ${ }^{1} \mathrm{H}-\mathrm{NMR}$ (Solvent: $\mathrm{D}_{2} \mathrm{O}$; Temperature: $25^{\circ} \mathrm{C}$ ) by the presence of protons from the benzene ring of PBA at ( $\delta=7.0$ ppm, 7.2 ppm and 7.4 ppm) (Supplementary Figure S4) .

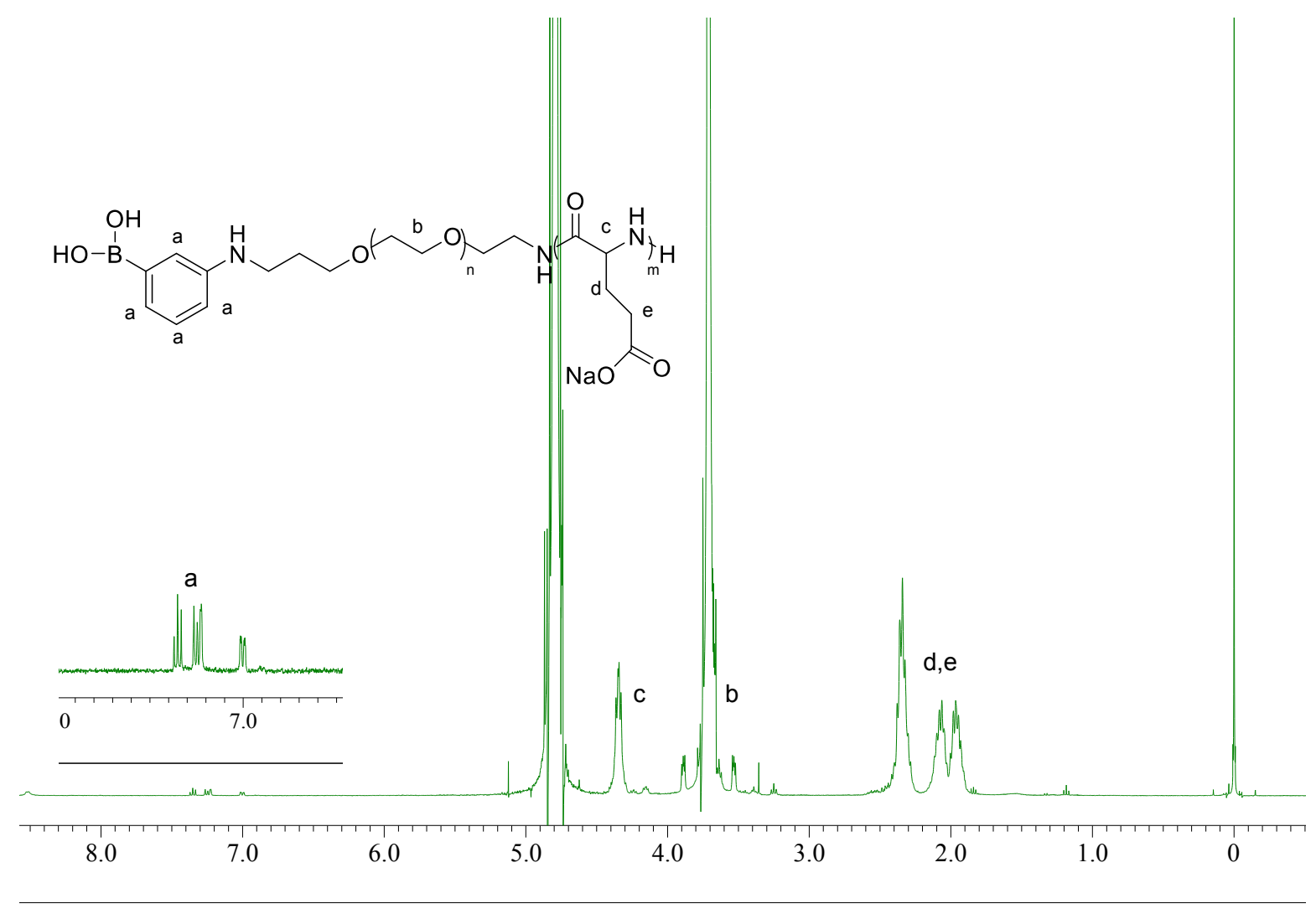

Supplementary Figure S4. ${ }^{1} \mathrm{H}-\mathrm{NMR}$ Spectra of $\mathrm{PBA}^{-P E G_{12 K}-b-P L G A}$ block copolymer. ${ }^{1} \mathrm{H}-\mathrm{NMR}$ measurement was done in $\mathrm{D}_{2} \mathrm{O}$ at $25^{\circ} \mathrm{C}$.

\subsection{Conjugation of Alexa Fluor 647 and Alexa Fluor 555 to block copolymers}

Methoxy-poly(ethylene glycol)-b-poly( $\gamma$-benzyl-L-glutamate) (MeO-PEG $10 \mathrm{~K}-b-\mathrm{PBLG})$ (molecular weight of PEG $\left(\mathrm{M}_{\mathrm{n}, \mathrm{PEG}}\right)=10,000$, degree of polymerization of PBLG $\left.\left(D_{\mathrm{PBLG}}\right)=40\right)$ was synthesized through similar manner as described above. The molecular weight distribution of $\mathrm{MeO}-\mathrm{PEG}_{10 \mathrm{~K}}-b-\mathrm{PBLG}$ were measured to be 1.02 by gel permeation chromatography (column: TSK-gel G3000 ${ }_{\mathrm{HHR}}, \mathrm{G} 4000_{\mathrm{HHR}}$ ) (Tosoh Co., Inc., Yamaguchi, Japan); eluent: DMF having $10 \mathrm{mM} \mathrm{LiCl}$; flow rate $0.8 \mathrm{ml} / \mathrm{min}$; detector: RI (refractive index); temperature: $25^{\circ} \mathrm{C}$ (Supplementary Figure S5A). Methoxy-poly(ethylene glycol)-b-poly(L-glutamic acid) (MeO-PEG ${ }_{10 K}-b$-PLGA) was obtained by deprotecting $\mathrm{MeO}-\mathrm{PEG}_{10 \mathrm{~K}}-b-\mathrm{PBLG}$ in $0.5 \mathrm{~N} \mathrm{NaOH}$ at room temperature overnight. Deprotection of the benzyl ester group was confirmed by ${ }^{1} \mathrm{H}-\mathrm{NMR}$ (solvent: 
$\mathrm{D}_{2} \mathrm{O}$; temperature: $25^{\circ} \mathrm{C}$ ) (Supplementary Figure S5B). MeO-PEG ${ }_{10 \mathrm{~K}}-b-\mathrm{PLGA}$ was labeled with fluorescent dye Alexa Fluor 647 and Alexa Fluor 555 carboxylic acid succinimidyl ester at the $\omega$-amino group of the polymer in $0.1 \mathrm{M} \mathrm{NaHCO}_{3}$ buffer. The reaction was done for $6 \mathrm{~h}$ in dark at room temperature. Polymer was then purified by using PD-10 column and lyophilized.
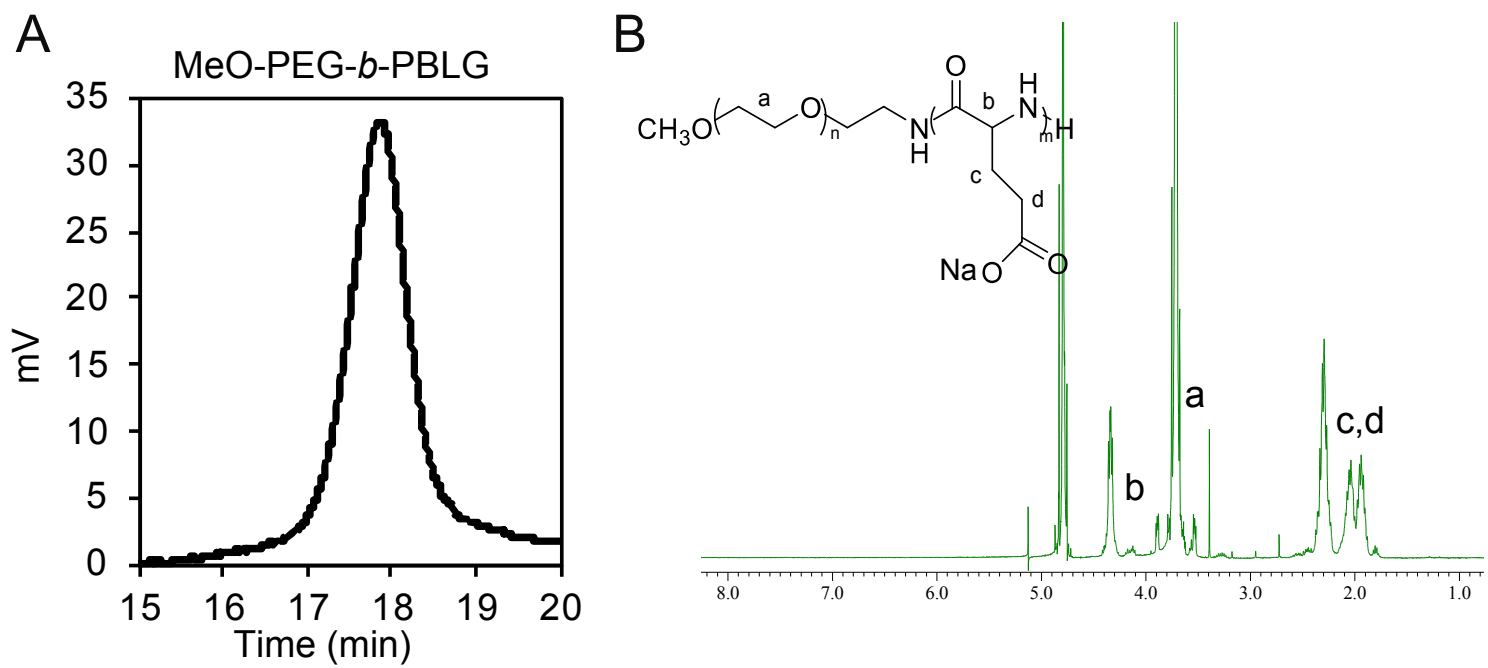

Supplementary Figure S5. A. GPC chromatograms of $\mathrm{MeO}-\mathrm{PEG}_{10 \mathrm{~K}}-b-\mathrm{PBLG}$ and B. ${ }^{1} \mathrm{H}-\mathrm{NMR}$ Spectra of MeO-PEG ${ }_{10 \mathrm{~K}}-b-\mathrm{PLGA}$. GPC was done in DMF containing $10 \mathrm{mM} \mathrm{LiCl}$ at $0.8 \mathrm{ml} / \mathrm{min}$ (detector: refractive index). ${ }^{1} \mathrm{H}-\mathrm{NMR}$ measurement was done in $\mathrm{D}_{2} \mathrm{O}$ at $25^{\circ} \mathrm{C}$.

\subsection{Binding constant of 5-BPA-PEG $5.5 K$-acetal}

We have previously confirmed the upholding of binding constant of propylamine conjugate of $5-\mathrm{BPA}^{3}$. To verify if the binding constant between 5-BPA conjugated polymer and sialic acid (SA) is conserved, we used 5-BPA-PEG ${ }_{5.5 K}$-acetal as a model polymer. To conjugate 5-BPA to polymer, 10 fold molar excess of 5-BPA were activated using DMT-MM in DMSO and added to a reaction mixture of 5 fold molar excess of amine-PEG ${ }_{5.5 \mathrm{~K}}$-acetal $(\mathrm{Mw}=5,500)$ with TEA. This reaction mixture was kept stirring for overnight. Polymer was then purified by dialysis first against DMSO then deionized water and lyophilized. The binding constant between 5-BPA-PEG ${ }_{5.5 K^{-}}$ acetal and SA was calculated by using a 3 component assay containing a fluorescent compound Alizarin red S (ARS) reported by Springsteen and Wang ${ }^{4,5}$. All fluorescence measurements were done by using fluorometer (Tecan Microplate Reader: Tecan infinite 200). The experimental and analysis of data was done by following scheme 
described by Springsteen and Wang ${ }^{4}$ (Supplementary Figure S6-S7). The binding constant between SA and 5-BPA-PEG $5.5 \mathrm{~K}$-acetal was found to be at $\mathrm{pH} 6.5 \mathrm{~K}_{\mathrm{SA}}=243$ $\mathrm{M}^{-1}$, at $\mathrm{pH} 6.9 \mathrm{~K}_{\mathrm{SA}}=177 \mathrm{M}^{-1}$ and at $\mathrm{pH} 7.4 \mathrm{~K}_{\mathrm{SA}}=52 \mathrm{M}^{-1}$. Thus, confirming preservation of binding constant between SA and 5-BPA after polymer conjugation.

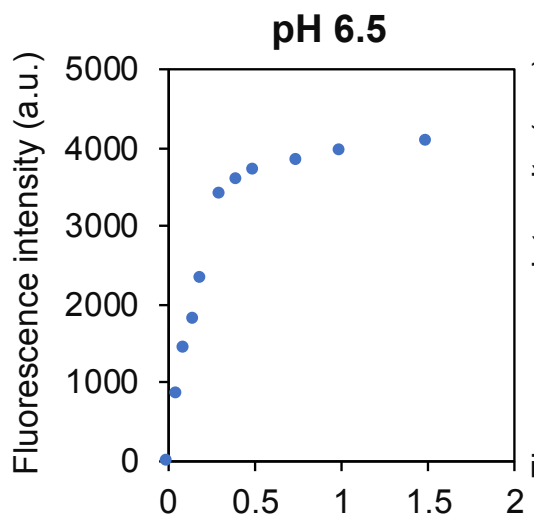

Concentration of 5-BPA-PEGAcetal $(\mathrm{mM})$
pH 6.9

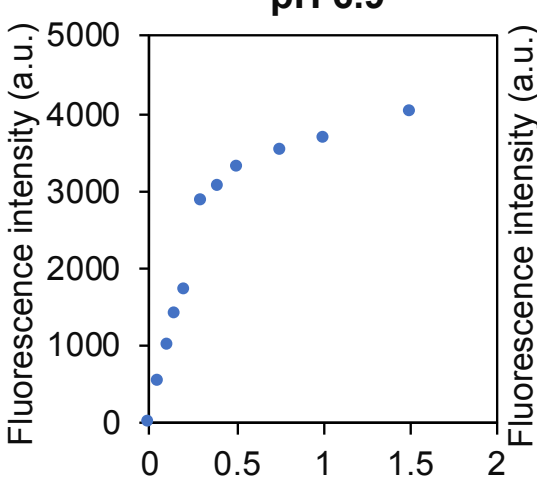

Concentration of 5-BPA-PEGAcetal $(\mathrm{mM})$
$\mathrm{pH} 7.4$

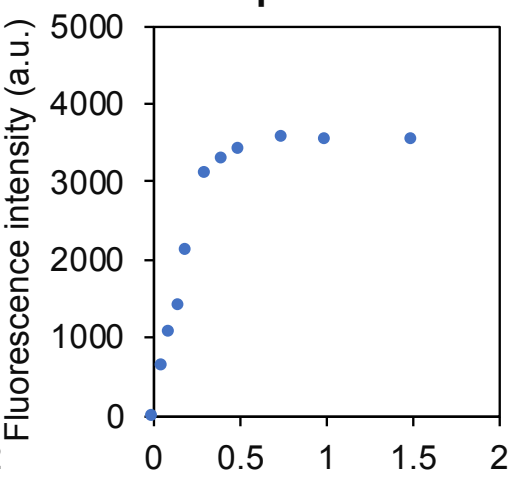

Concentration of 5-BPA-PEGAcetal $(\mathrm{mM})$

Supplementary Figure S6. Increased florescence intensity (ex: 468 nm, em: 572 nm) of $9 \mu \mathrm{M}$ ARS solutions with increased concentration of $5-B P A-P E G_{5.5 k}$-acetal in $\mathrm{pH}$ 6.5, $\mathrm{pH} 6.9$ and $\mathrm{pH}$ 7.4. Data are presented as average \pm standard deviation (S.D.), $(n=3)$.

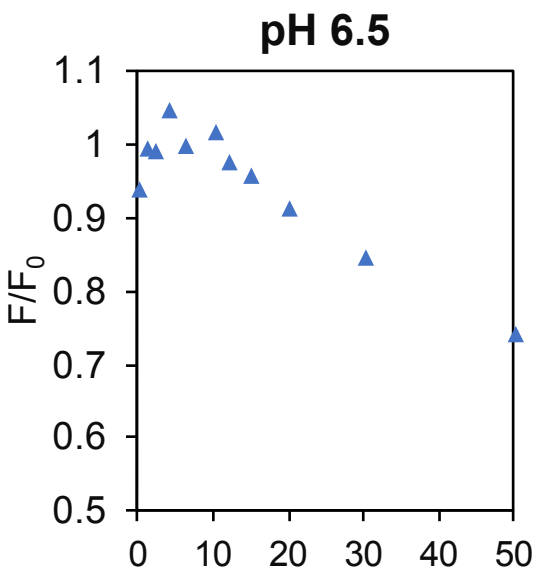

Concentration of $[\mathrm{SA}]$ $(\mathrm{mM})$

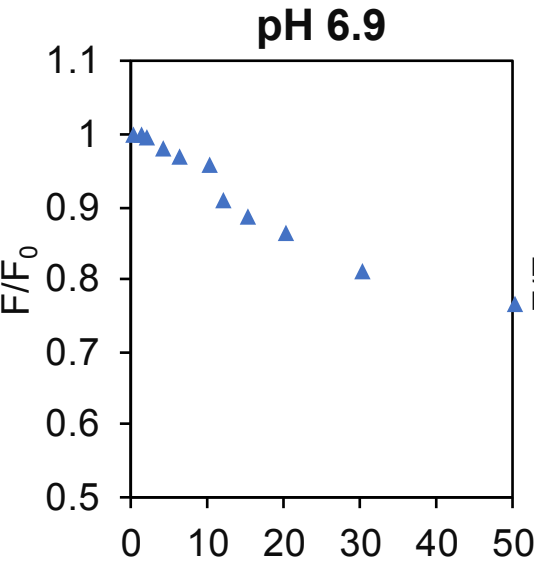

Concentration of $[\mathrm{SA}]$ (mM)

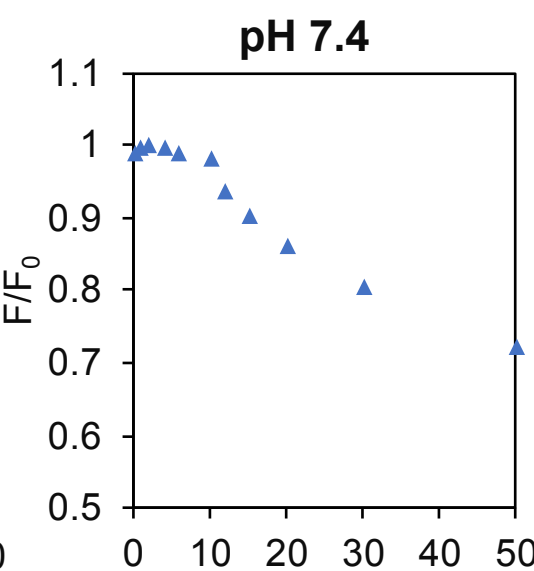

Concentration of [SA] (mM)

Supplementary Figure S7. Decrease of florescent intensity (ex: 468 nm, em: 572 $\mathrm{nm}$ ) of ARS-5-BPA-PEG ${ }_{5.5 \mathrm{k}}$-acetal complex by presence of SA at $\mathrm{pH} 6.5, \mathrm{pH} 6.9$ and $\mathrm{pH}$ 7.4. Data are presented as average \pm standard deviation (S.D.) $(n=3)$. $F_{0}$ : Initial fluorescence intensity of solution. F: Fluorescence intensity of solution. 


\subsection{Cellular uptake of micelles}

HSC2 cells $\left(2 \times 10^{4}\right.$ cells $\left./ 200 \mu \mathrm{l}\right)$ were plated on 8 Chambered \# 1.0 Borosilicate Cover glass system (Lab Tek). After $48 \mathrm{~h}$ incubation, medium was replaced with $\mathrm{pH}$ 7.4 and $\mathrm{pH} 6.5$ cell culture medium with $5.5 \mathrm{mM}$ glucose concentration, which is comparable to blood glucose concentration containing Alexa Fluor 647-labeled PBADACHPt/m or 5-BPA-DACHPt/m (500 mM on a DACHPt basis). Fluorescence imaging of the live cells was done at 3-, 6- and 9-h after incubation by using CLSM (Zeiss LSM780, Carl Zeiss, Germany) Cells were also stained with Lysotracker green DND26 before imaging for marking the late endosomes/lysosomes (Supplementary Figure S8).

A
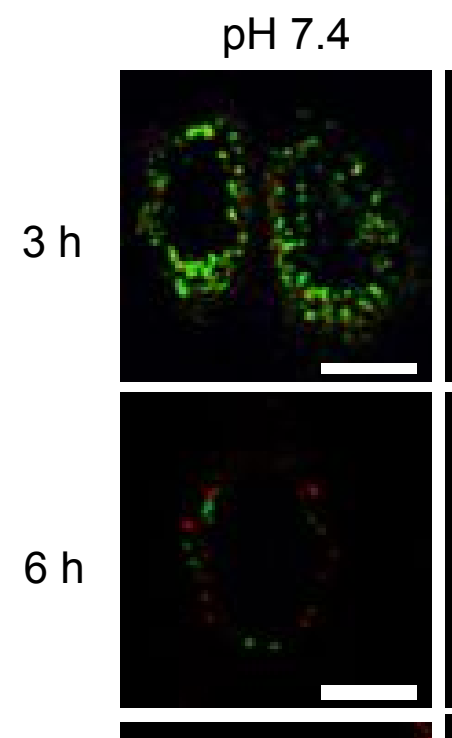

$9 \mathrm{~h}$

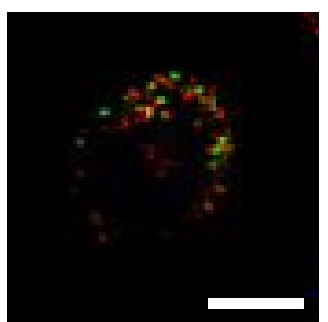

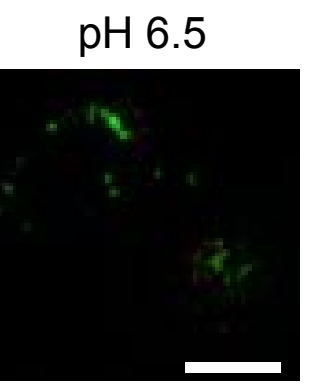
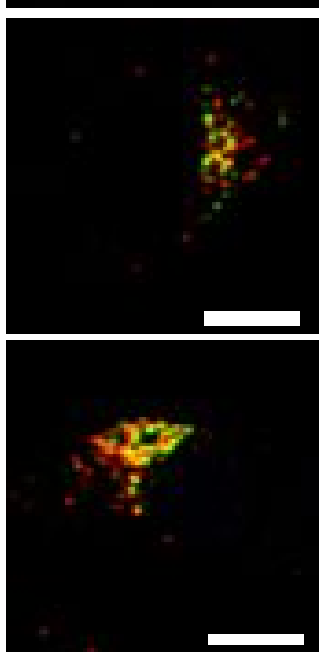

B
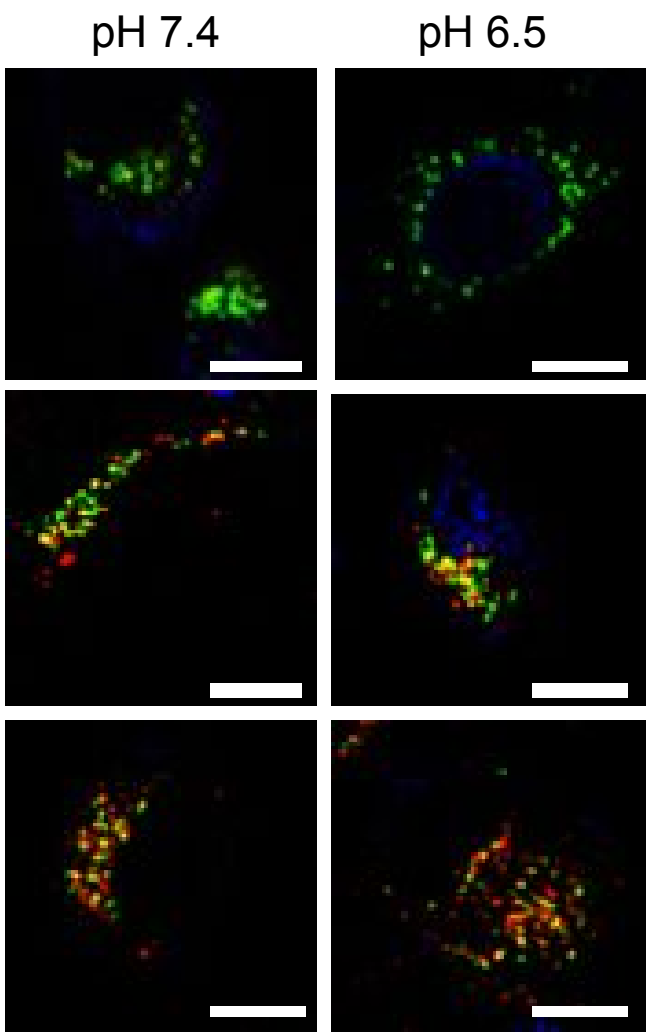

5-BPA/PBA-DACHPt/m/Lysotracker/COLOCALIZATION

Supplementary Figure S8. In vitro micro distribution of micelles in HSC2 cells after 3-,6- and 9 h incubation at pH 7.4 and pH 6.5. A. Alexa Fluor 647-labeled 5-BPADACHPt/m (red). B. Alexa Fluor 647-labeled PBA-DACHPt/m (red). Late endosomes and lysosomes were stained by using Lysotracker Green (green). Colocalization is shown as yellow. Cell nuclei was stained with DAPI (blue). Scale bars $=10 \mu \mathrm{m}$. 


\subsection{Confirmation of SA cleavage from cell surface by sialidase treatment}

To verify removal of SA from HSC2 cells through enzymatic hydrolysis using sialidase, $\mathrm{N}$-acetylgalactosamine (GalNAc), the sugar next to SA, was stained. GaINAc becomes uncovered after removal of SA. Helix pomatia agglutinin (HPA) is a lectin specific to GalNAc $6.2 \times 10^{4}$ HSC2 cells $/ 200 \mu$ l were plated on 8 Chambered \# 1.0 Borosilicate Cover glass system (Lab Tek). After $48 \mathrm{~h}$ incubation, medium was replaced with $\mathrm{pH} 5$ acetate buffer with and without sialidase for $2 \mathrm{~h}$. Then cells were washed twice with PBS and incubated with Alexa Fluor 488-labeled HPA (1mg/20ml) for $5 \mathrm{~min}$ on ice. Finally, the cells were stained with DAPI and imaged using Leica DMi8 inverted microscope. Image analysis was done using ImageJ software. Cells that were treated with sialidase demonstrated very high amount of HPA staining compared to non-treated cells which had almost no staining of HPA on cells (Supplementary Figure S9). Such elevated staining of GaINAc verifies cleaving of SA by sialidase enzyme.
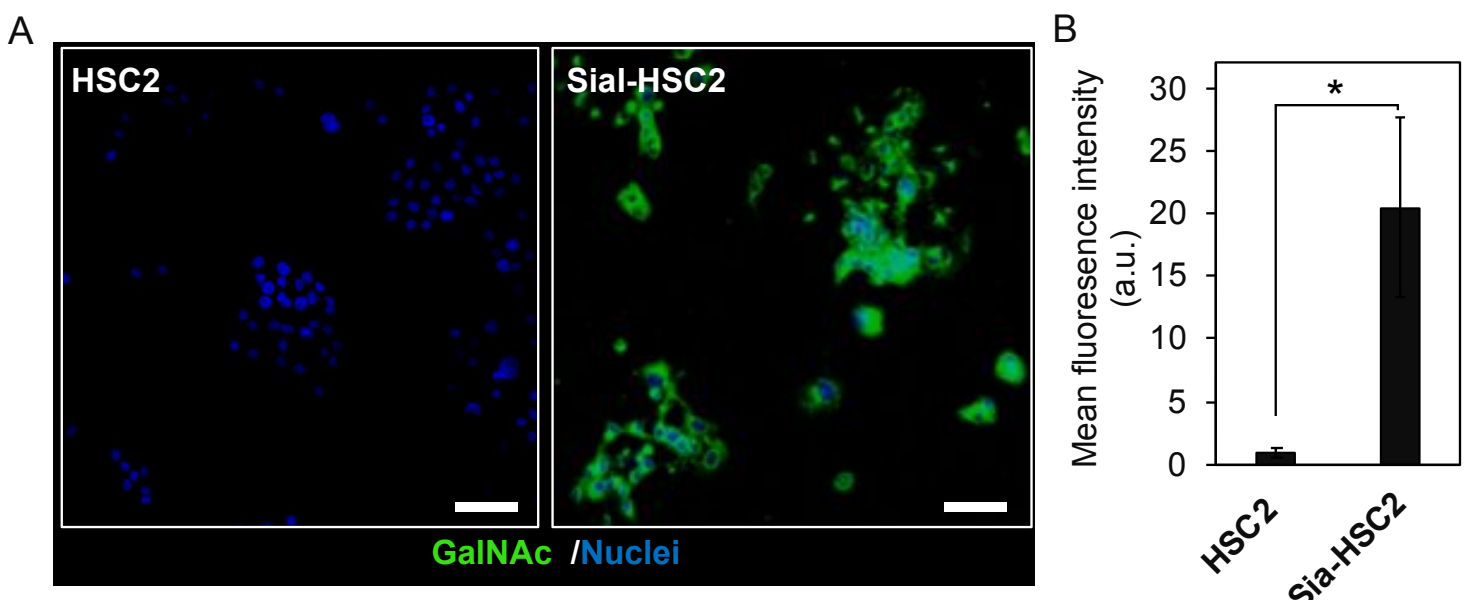

Supplementary Figure S9. Staining of GalNAc after SA was cleaved enzymatically with sialidase to expose GalNAc (green). A. Staining of GalNAc (green) and cell nuclei (blue) in HSC2 and sialidase treated HSC2 in vitro. B. Quantification of mean fluorescence intensity of GalNAc (green) in HSC2 with and without sialidase treatment in vitro. Data are presented as average \pm standard deviation (S.D.) $(n=3)$. Scale bars $=$ $100 \mu \mathrm{m} .{ }^{*} p<0.005$ calculated by Student's t tests

\subsection{Analysis of stemness in different $\mathrm{pH}$}

To understand the effect of $\mathrm{pH}$ on CSC population in vitro, cells were incubated with $\mathrm{pH} 6.5$ or $\mathrm{pH} 7.4$ media. After incubation for $24 \mathrm{~h}$, the cells were collected using trypsin and washed with $2 \%$ FBS containing PBS. Unspecific binding was blocked by using 
Blocking One solution (Nacalai Tesque, Kyoto, Japan) for $25 \mathrm{~min}$. Then, the cells were washed and incubated with anti-CD44v9 antibody clone RV3 (anti-human, rat; Cosmobio) in PBS for 45 min on ice. After 2 times washing with PBS, the cells were resuspended in $50 \mu$ l Alexa Fluor 488-conjugated secondary antibody and incubated for $30 \mathrm{~min}$ in dark on ice. Finally, the cells were stained with DAPI $(0.03 \mathrm{mg} / \mathrm{ml})$, washed and suspended in $1 \mathrm{ml}$ PBS (containing 2\% FBS). The cells were then analyzed using Flow cytometer (Becton Dickinson, Franklin Lakes, NJ, USA) and FlowJo software. The change in media $\mathrm{pH}$ did not instigate any significant difference in the CSC population in HSC2 cells (Supplementary Figure S10. A, B and C).

A
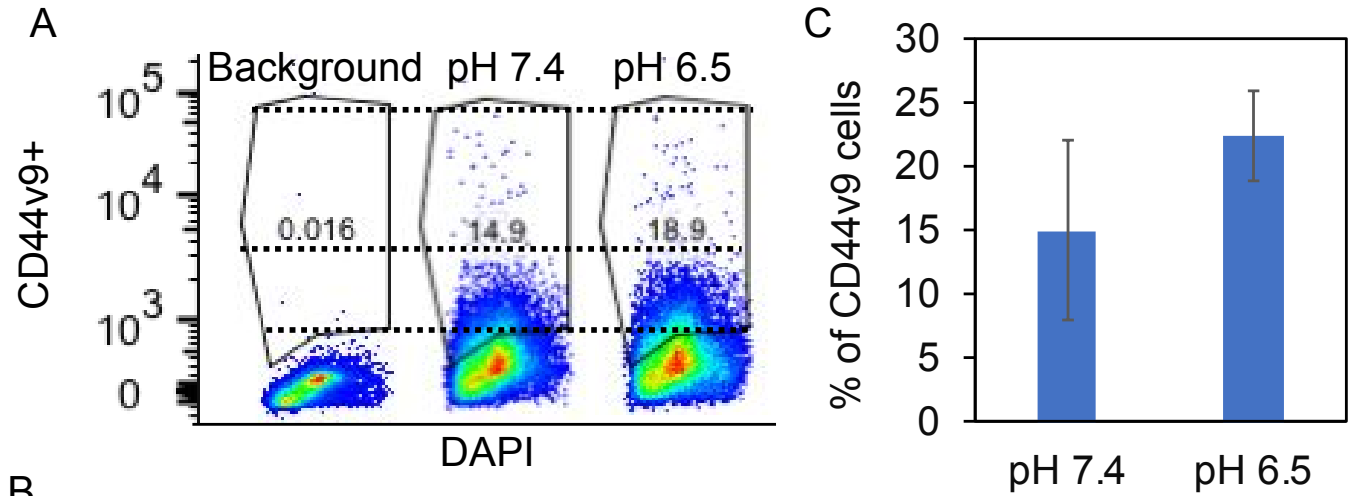

B
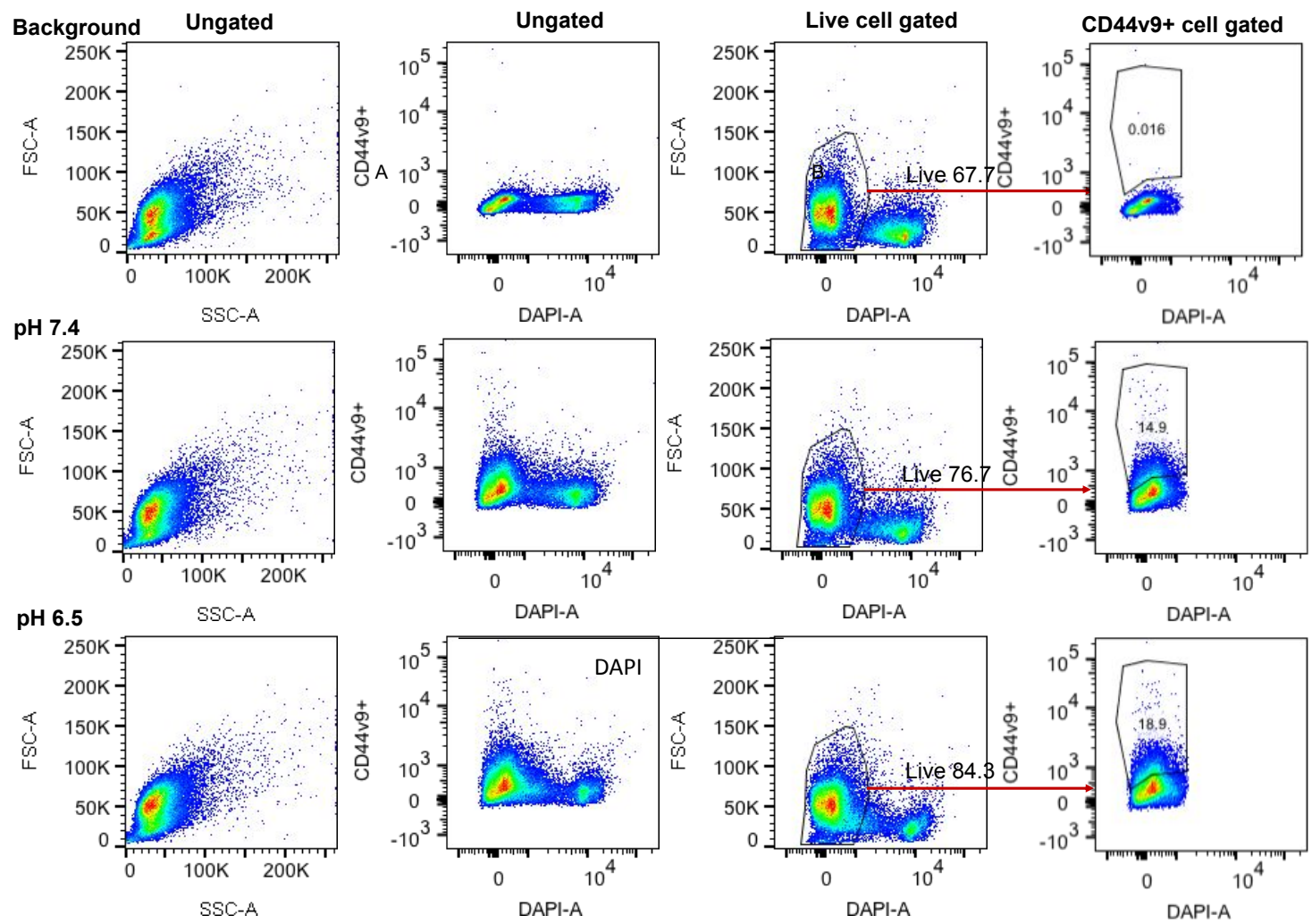

Supplementary Figure S10. Effect of media $\mathrm{pH}$ on CSCs in vitro. A and $\mathbf{B}$. Expression of CD44v9 on HSC2 cells measured by flow cytometry $24 \mathrm{~h}$ after 
incubation at $\mathrm{pH} 6.5$ and $\mathrm{pH}$ 7.4. C. Flow cytometry correlograms for the quantification of CD44v9 expression. Data are expressed as average \pm S.D., $n=4$.

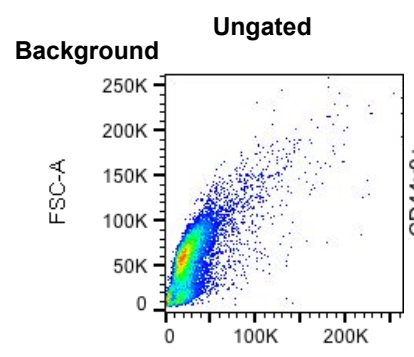

PBS

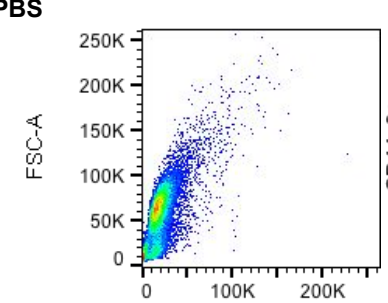

SSC-A

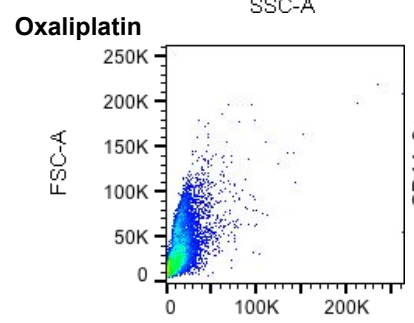

SSC-A

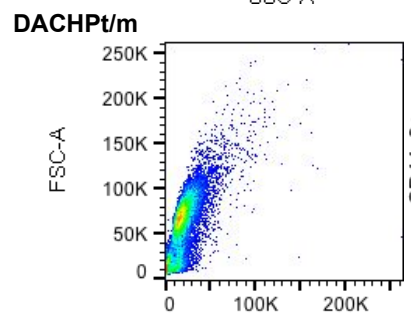

PBA-DACHPt/m

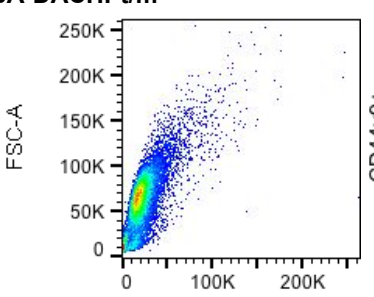

SSC-A

5-BPA-DACHPt/m

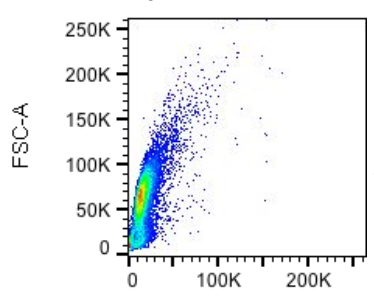

SSC-A
Ungated

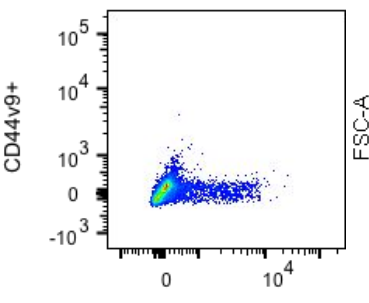

DAPI-A
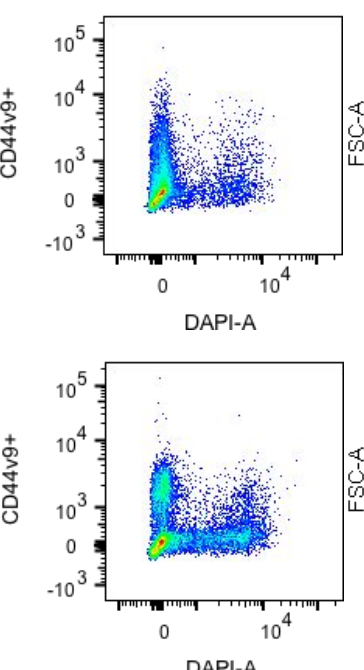

DAPI-A

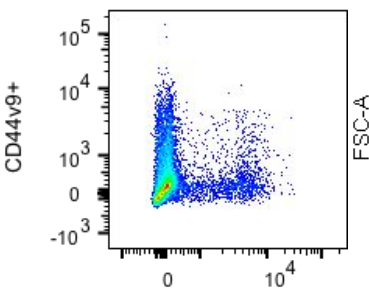

DAPI-A
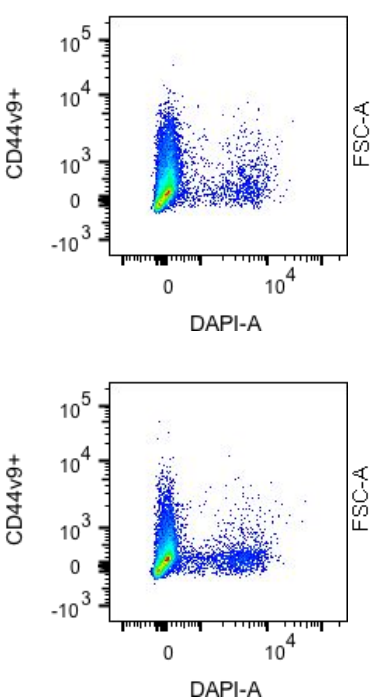

Live cell gated
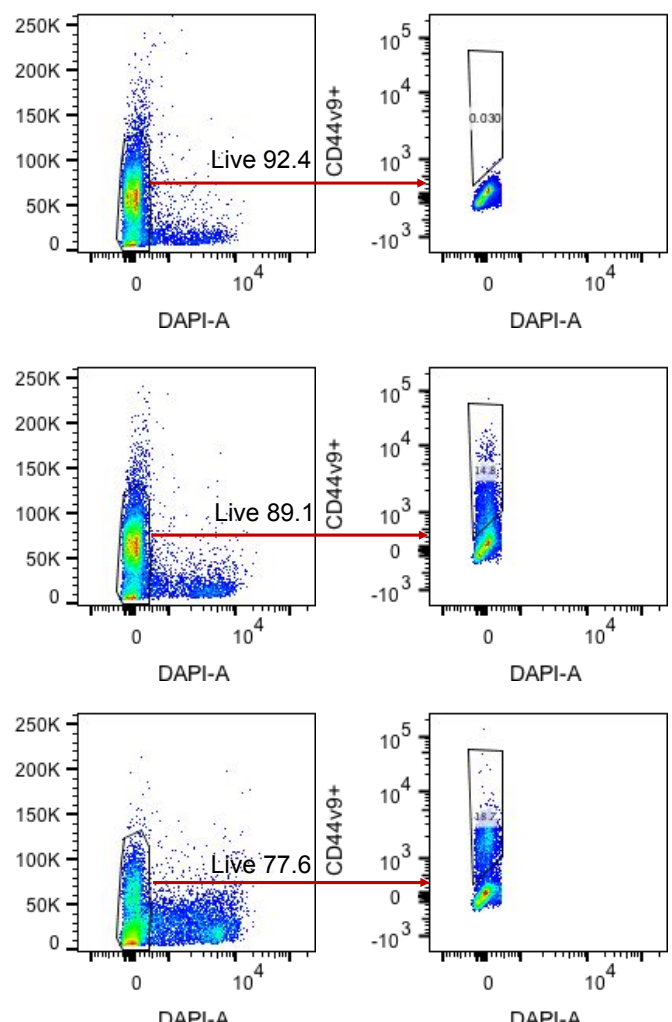

DAPI-A
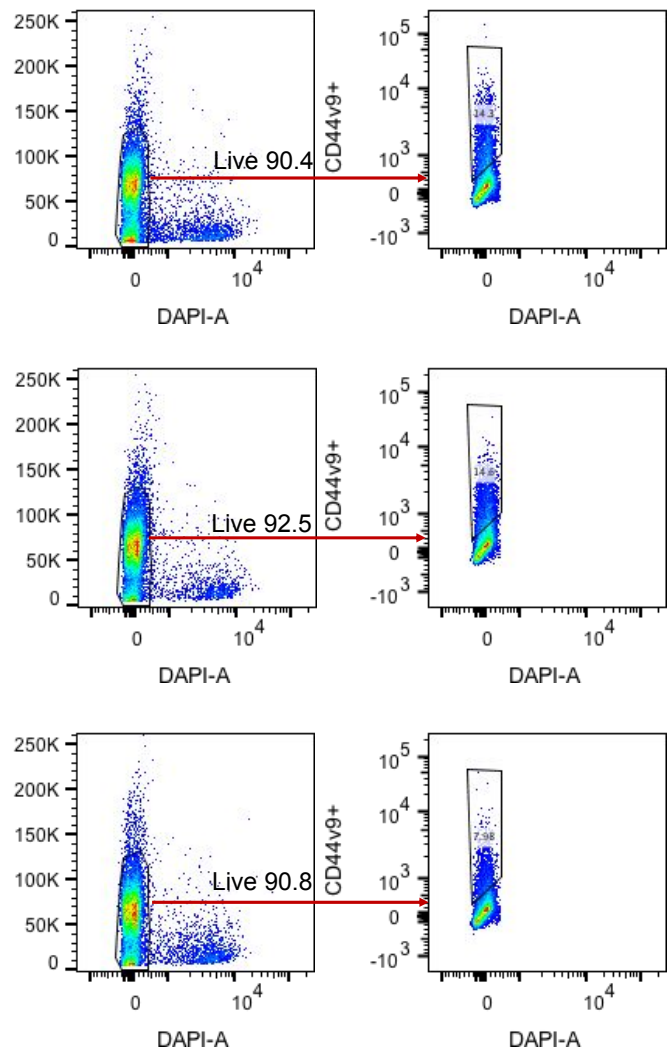

Supplementary Figure S11. Expression of CD44v9 on HSC2 cells measured by flow 
cytometry $24 \mathrm{~h}$ after treatment with PBS, free oxaliplatin, DACHPt/m, PBA-DACHPt/m or 5-BPA-DACHPt/m.

\subsection{Interaction of the micelles with the cellular components of blood}

To evaluate any unspecific interaction of ligand installed micelles with blood component, 6 weeks-old female BALB/c nu/nu mice were injected with $\mathrm{DACHPt} / \mathrm{m}$, PBA-DACHPt/m and 5-BPA-DACHPt/m at $5 \mathrm{mg} / \mathrm{kg}$ on a DACHPt basis via tail vein. After 1-, 4-, 8-, 24- and 48-h of drug injection, mice were sacrificed and blood was collected from the inferior vena cava. Blood components were collected after centrifugation (rpm: 1000), weighed and digested by using $90 \% \mathrm{HNO}_{3}$. After evaporating all $90 \% \mathrm{HNO}_{3}$, the dried samples were reconstituted in $1 \mathrm{ml}$ of $1 \% \mathrm{HNO}_{3}$ and DACHPt was then measured by ICP-MS after filtering through $0.45 \mu \mathrm{m}$ filter. All data was evaluated using Agilent Masshunter Workstation software. The amount of DACHPt in each time point was normalized to the non-ligand DACHPt/m. There were no significant differences between the micelle groups (Supplementary Figure S12), ensuring that there is no noteworthy interaction of PBA-DACHPt/m and 5-BPADACHPt/m with blood cells. Such phenomenon is possibly due to the $5 \mathrm{mM}$ glucose concentration in blood and greater binding of boronic acid to glucose at $\mathrm{pH} 7.4^{3,7}$ compared to SA thus hindering interaction of PBA-DACHPt/m and 5-BPA-DACHPt/m in bloodstream.

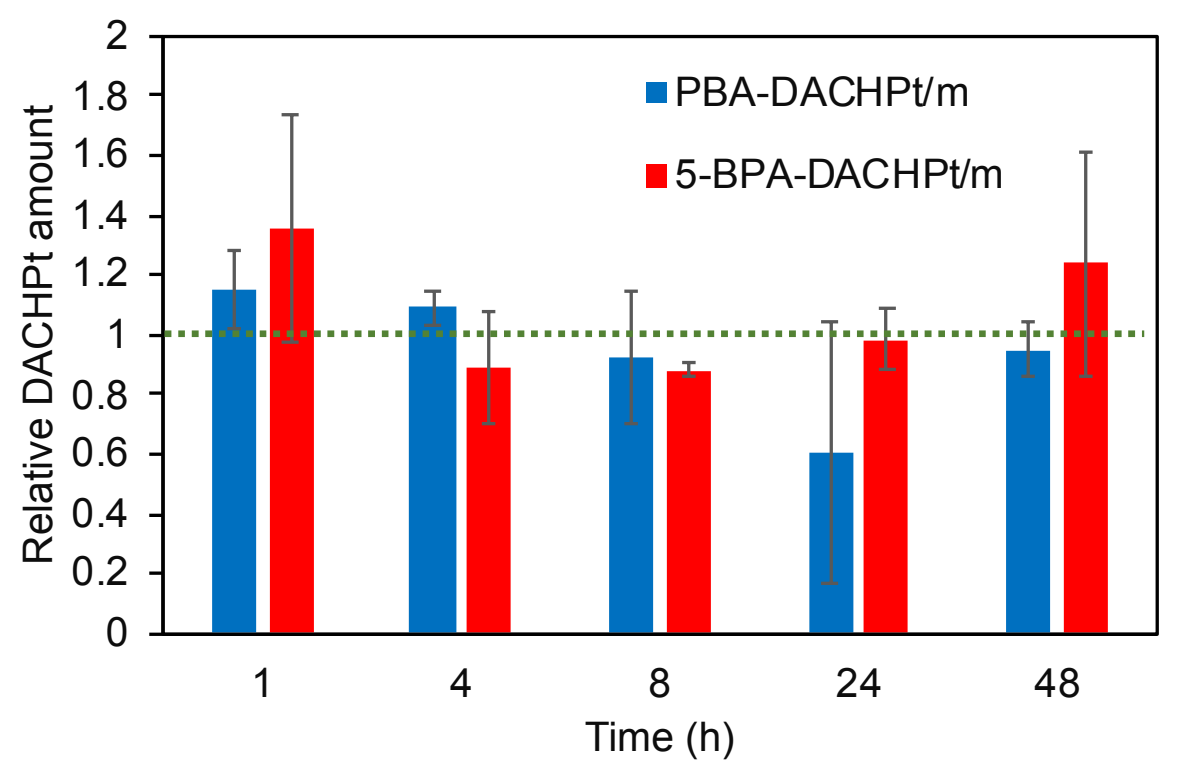

Supplementary Figure S12. Quantification of the amount of DACHPt in the cellular components of blood after intravenous injection of micelles. The data were normalized 
to the amount of DACHPt from non-ligand DACHPt/m at each time point. All the micelles had comparable levels of DACHPt relative to non-ligand DACHPt/m verifying no unspecific interaction between SA expressing components, mainly erythrocytes and 5-BPA or PBA ligand.

\subsection{Analysis of expression of sialic acid in cells}

SA expression of in vitro cultured HSC2 cell line was quantified using NANA assay kit. Cells were lysed and incubated with sialidase for overnight to release SA from the cell surface. Cells were heated at $95^{\circ} \mathrm{C}$ for $5 \mathrm{~min}$ and supernatant was collected after centrifugation for quantification. Quantification was done by following the protocol provided with the NANA assay kit per million cells. Thus, the amount of SA on in vitro cultured human head and neck cancer cell line HSC2 was determined through releasing surface SA using sialidase and generating a standard curve from pure SA provided with the assay kit. The SA amount was determined to be $\sim 1 \mu \mathrm{mol} / 10^{9}$ cells.

\subsection{Analysis of expression of sialic acid in human tumor samples}

Recovery of antigens of head and neck cancer with normal tissue array (HN483a) was done by incubating slide in 100\% Xylene, 100\% Ethanol, 90\% Ethanol, 70\% Ethanol and two times in distilled water for 5 min each. Then the slide was heated at $95^{\circ} \mathrm{C}$ in citric acid buffer ( $\mathrm{pH} 6)$ for 30min. Finally, slide was incubated in PBS ( $\mathrm{pH} 7.4)$ in room temperature for $20 \mathrm{~min}$ and $5 \mathrm{~min}$ under running water. Tissue samples were incubated with Alexa Fluor 488-labeled WGA (1mg/ 20ml in PBS) for $2 \mathrm{~h}$ and washed 3 times. Finally, nuclei were stained with DAPI $(0.03 \mathrm{mg} / \mathrm{ml}$ in PBS) for $5 \mathrm{~min}$ before mounting with a cover glass. The slide was then imaged by using CLSM (Zeiss LSM 780, Carl Zeiss, Germany). Quantification of SA staining revealed relative 6-fold higher expression of SA on cancerous tissues compared to non-cancerous tissues (Supplementary Figure S13). This validates the approach of using a SA targeting system to specifically direct nanomedicine to cancer cells. 

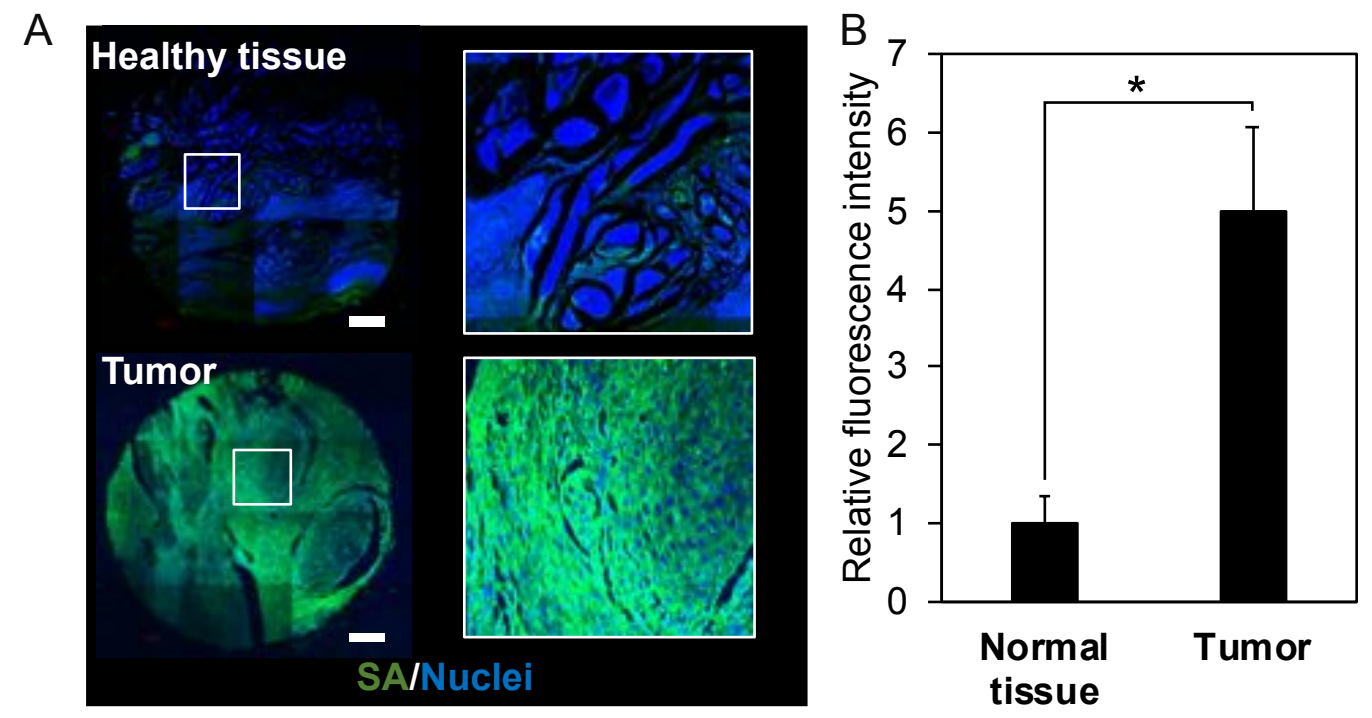

Supplementary Figure S13. Staining of SA in human tissue array (healthy tissue and tumor). A. Representative microscopic images of healthy tissue (tongue; upper panel) and tumor (tongue; lower panel). SA was stained with WGA (green) and nuclei with DAPI (blue). White square insets are the areas for magnification. Scale bars $=200$ $\mu \mathrm{m}$. B. Quantification of the relative fluorescence intensity of SA in healthy tissue and tumor. Data are presented as average \pm standard deviation (S.D.) $(n=3) . \quad{ }^{*} p<0.01$ calculated by Student's $t$ test.

\section{References:}

(1) Miura, Y.; Takenaka, T.; Toh, K.; Wu, S.; Nishihara, H.; Kano, M.R.; Ino, Y.; Nomoto, T.; Matsumoto, Y.; Koyama, H.; Cabral, H.; Nishiyama, N.; Kataoka, K. Cyclic RGD-linked polymeric micelles for targeted delivery of platinum anticancer drugs to glioblastoma through the blood-brain tumor barrier. ACS Nano 2013, 7, 8583-8592.

(2) Deshayes, S.; Cabral, H.; Ishii, T.; Miura, Y.; Kobayashi, S.; Yamashita, T.; Matsumoto, A.; Miyahara, Y.; Nishiyama, N.; Kataoka, K. Phenylboronic Acid-Installed Polymeric Micelles for Targeting Sialylated Epitopes in Solid Tumors. J. Am. Chem. Soc. 2013, 135, 15501-15507.

(3) Matsumoto, A.; Stephenson-Brown, A. J.; Khan, T.; Miyazawa, T.; Cabral, H.; Kataoka, K.; Miyahara, Y. Heterocyclic boronic acids display sialic acid selective binding in a hypoxic tumor relevant acidic environment. Chem. Sci. 2017, 8, 61656170. 
(4) Springsteen, G.; Wang, B. Alizarin Red S. as a general optical reporter for studying the binding of boronic acids with carbohydrates. Chem. Commun. 2001, 1608-1609.

(5) Springsteen, G.; Wang, B. A detailed examination of boronic acid-diol complexation. Tetrahedron 2002, 58, 5291-5300.

(6) Sanchez, J.F.; Lescar, J.; Chazalet, V.; Audfray, A.; Gagnon, J.; Alvarez, R.; Breton, C.; Imberty, A.; Mitchell, E.P. Biochemical and Structural Analysis of Helix pomatia Agglutinin. J. Biol. Chem. 2006, 281, 20171-20180.

(7) Otsuka, H.; Uchimura, E.; Koshino, H.; Okano, T.; Kataoka, K. Anomalous binding profile of phenylboronic acid with $\mathrm{N}$-acetylneuraminic acid (Neu5Ac) in aqueous solution with varying pH. J. Am. Chem. Soc. 2003, 125, 3493-3502. 